\title{
Do salt storage practices affect the iodine content of salt? - A school-based study in North India
}

M Athar Ansari ${ }^{1}$, Zulfia Khan ${ }^{2}$, Ali Jafar Abedi $^{3}$

${ }^{1}$ Professor, Department of Community Medicine, Jawaharlal Nehru Medical College, Aligarh Muslim University, Aligarh-202002, India; ${ }^{2}$ Professor (Retired), Department of Community Medicine, Jawaharlal Nehru Medical College, Aligarh Muslim University, Aligarh-202002, India; ${ }^{3}$ Assistant Professor, Department of Community Medicine, Jawaharlal Nehru Medical College, Aligarh Muslim University, Aligarh-202002, India

\begin{tabular}{|c|c|c|c|c|c|c|c|}
\hline Abstract & Introduction & Methodology & Results & Conclusion & References & Citation & Tables / Figures \\
\hline
\end{tabular}

\section{Corresponding Author}

Dr M. Athar Ansari, Professor, Department of Community Medicine, Jawaharlal Nehru Medical College, Aligarh Muslim University, Aligarh-202002, India

E Mail ID: atharansari777@rediffmail.com

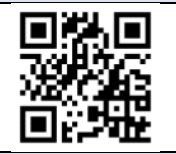

\section{Citation}

Ansari MA, Khan Z, Abedi AJ. Do salt storage practices affect the iodine content of salt? - A school-based study in North India. Indian J Comm Health. 2021;33(1):161-168. https://doi.org/10.47203/IJCH.2021.v33i01.022

Source of Funding: Nil Conflict of Interest: None declared

\section{Article Cycle}

\begin{tabular}{|c|}
\hline Received: $18 / 12 / 2020 ;$ Revision: 24/01/2021; Accepted:14/02/2021; Published:31/03/2021 \\
\hline This work is licensed under a Creative Commons Attribution 4.0 International License. \\
\hline
\end{tabular}

\section{Abstract}

Introduction: In India, IDD has been identified as a public health problem. At present best source for iodine supplementation is iodinated salt in the form of "lodised Salt" containing potassium iodide (KI) and "lodated Salt" containing potassium iodate (KIO3). Objectives: To find out salt storage practices in the houses and association of storage practices and iodine content. Methods: From 1st to 5th standard children (age group 6-12 years) were the "sampling units." The required sample was selected by "Multistage sampling" by doing a sub-sampling. The sample size (N) calculated was 879 . However, a total of 950 participants were included in the study. To check on spot salt storage practices, 70 families of school children were visited. The iodine content of salt samples was tested with spot testing kit (STK). Results: Out of 950 students, most of them (92.1\%) used to take powdered salt. Out of 915 salt samples, collected, $79.0 \%$ samples were iodized and only $16.1 \%$ of salt samples had $>15$ ppm iodine content. Salt was kept in containers in $36(51.4 \%)$ houses, but only 6 (8.7\%) families were using airtight containers. The percentage of nil iodine was highest in open packets (35.7\%). As the distance of salt storage from chullah increased, the level of iodine content was also improved. Conclusions: School children and their families should be told about the importance of taking adequately iodized salt and to follow correct salt storage practices. Sustained IEC activities should be carried out more vigorously to sensitize the students and community.

\section{Keywords}

lodine Deficiency; lodised Salt; Parts Per Million (PPM); Salt Storage Practices

\section{Introduction}

lodine deficiency is so easy to prevent that it is a crime to let a single child be born mentally handicapped for the reason."

\section{H. Labouisse, Executive Director, UNICEF (1978)}

lodine deficiency is one of the most neglected and widespread of all nutritional deficiencies, constituting a brake on human development. lodine is required for the synthesis of thyroxine (T4) and triiodothyronine (T3). These hormones are very important in the regulation of the metabolism of proteins, carbohydrates, and fats, and almost all the activities of the body.

The two most recognized features of iodine deficiency in the past like endemic goiter and cretinism are the tip of the "IDD ICEBERG." Goiter is 
indeed the visually obvious and familiar feature of iodine deficiency but the understanding of the other consequences of iodine deficiency has greatly expanded in the last 25 years so that it is not surprising that the wider designation "IDD" is now considered more appropriate. (1)

In India, IDD has been identified as a public health problem. It has been observed that the world's most intense goiter belt is in India stretching 2400 Kilometres from Kashmir in the North West to the Naga Hills in the East. In addition to the known Himalayan endemic belt, iodine deficiency and endemic goiter have been reported from many other states in the country as well. New pockets of iodine deficiency are being identified continuously. Surveys conducted in India have revealed that out of the 325 districts surveyed in India, 263 districts are IDDendemic, i.e. the prevalence of IDD is above 10 percent in the population. (2) Out of the total population of India (approx 1200 million), more than 200 million are at risk of IDD. (3) WHO has recommended that for assessment of lodine deficiency in an area, children in the age group 6-12 years should be surveyed. (4)

According to the World Health Organization (WHO), iodine deficiency occurs in 130 countries in the world, and 2.2 billion people live in iodine-deficient areas. (5) Surveys conducted in India have revealed that out of the 325 districts surveyed in India, 263 districts are IDD-endemic, i.e., the prevalence of iodine deficiency disorder (IDD) is above $10 \%$ in the population. (6)

At present best source for iodine supplementation is iodinated salt in the form of "lodised Salt" containing potassium iodide (KI) and "lodated Salt" containing potassium iodate $\left(\mathrm{KIO}_{3}\right) . \mathrm{KIO}_{3}$ has an advantage over $\mathrm{KI}$ in that it is more stable and has a longer shelf life. The other methods of iodine supplementation are injection of iodized oil, the addition of iodine to bread, and iodination of irrigation water but these methods do not apply to all people. (7)

After trying many methods, salt emerges as the best vehicle for iodine supplementation. After the iodization of salt, it is to be made mandatory that it should contain 30 parts per million ( $\mathrm{ppm}$ ) iodine at the manufacturer level and $15 \mathrm{ppm}$ at the distribution channel including the consumer level. If salt with the recommended level of iodine is consumed by a community for just 12 months, no more cretins will be born, no more babies will suffer from retarded physical or mental development attributed to iodine deficiency.

\section{Aims \& Objectives}

1. To find out salt storage practices in the houses.

2. To find out the association of storage practices and iodine content in salt samples.

\section{Material \& Methods}

The study was conducted among school children (612 years). Three government and four private schools in Aligarh were selected.

Sampling unit: 1st to 5th standard children of the schools (age group 6-12 years) were the "sampling units" for the study conducted in schools. This is the preferred group as it is usually accessible. There is a practical reason for not measuring very young age groups. The smaller the child, the smaller the thyroid and it is more difficult to perform palpation. (4) In the selected schools, almost every child of the 1st standard had completed six years of age and most of the children of the 5 th standard were completing twelve years of age.

Sample Size: From 1st to 5th standard children (age group 6-12 years) were the "sampling units." Directorate General of Health Services found a goiter prevalence rate of $12 \%$ in Aligarh District. (8) Taking " $p$ " as $12 \%$ and relative error (I) $20 \%$ of "p," the sample size $(\mathrm{N})$ was calculated as (9)

$$
\begin{aligned}
& N=4 \times P \times q / / 2 \\
& q(\%)=100-p, \\
& N=4 \times 12 \times 88 /(0.2 \times 12) 2 \\
& N=733
\end{aligned}
$$

Taking into consideration the $20 \%$ nonresponse/non-cooperation rate, the total sample size was:

$$
\begin{aligned}
& N=733+(0.2 \times 733) \\
& N=879
\end{aligned}
$$

However, a total of 950 participants were included in the study.

Plan of Study: Schools were contacted several days before the study began to inform the principals of the schools, the study purpose, and to get consent from them as well as parents/guardians of children. In consultation with the principal, a suitable date (a day on which the attendance in the school was maximum, preferably early in the week, avoiding national and state holidays), time, and place for interviewing and examining the children were chosen. As a part of ethical considerations, they were briefed about the presentation of IDD, and its consequences and methods available for its 
prevention especially the health benefits of taking iodized salt in diet, food items that prevent the utilization of iodine in the body. This helped us having their maximum participation in conducting the study in school children, and it also ensured good attendance of students.

The school authorities were asked to provide us the list of students who were enrolled in classes from 1st to 5th standards and were in the age group 6-12 years. We requested school records showing their dates of births. The age was classified according to their dates of births.

Sampling Procedure: The required sample was selected by "Multistage sampling" by doing a subsampling. In the first stage, schools were selected over a period of time, and permission was obtained from school authorities. In the second stage, a list of students in class $1^{\text {st }}-5$ th standard between the age of 6-12 years was obtained. Our "sampling frame" consisted of the number of students selected from one school. As per the probability proportional to size method, the number of students in a school was proportional to the strength of the total number of students (6-12 years) from all schools. The next stage was to select students in a school. With the help of a random number table, a random sampling method was applied to select the final numbers of students from a school to be included in the study. We assigned each student a serial number in that school. Every child was asked to bring approximately two teaspoons $(10 \mathrm{gm})$ of salt in labeled auto sealed polythene pouches.

\section{Inclusion Criteria}

1. Students of schools whose principals gave consent to our study.

2. Students of classes from 1st to 5 th standard who were of age group 6-12 years.

3. Students whose parents/guardians gave consent to our study.

4. Students who brought salt samples for testing

Exclusion Criteria

1. Students not attending the school on the day of study.

2. Students whose parents/guardians did not give consent to our study.

3. Students aged less than 6 years and more than 12 years

4. Students who did not bring salt samples for testing in given sachet

Salt Testing: Every child was asked to bring approximately two teaspoons (10 gm) of salt being used for cooking in their respective households, in labeled auto sealed polythene pouches. For community or population surveys, $10 \mathrm{gm}$ salt samples are sufficient. (10)

To check on spot salt storage practices, 70 families of school children were visited.

The iodine content of salt samples was tested using the spot testing kit (STK) in the school in front of students and teachers, in halls/schools of residence of Aligarh Muslim University, and the community. This method is similar to the National Family Health Survey estimates conducted in the year 2005-06.(11) Approval of Institutional Ethics and Research Advisory Committee, Faculty of Medicine, J.N. Medical College, A.M.U., Aligarh, India was also taken.

Statistical analysis was done using IBM SPSS version 20. Chi-square was used to find out association and a ' $p$ ' value of $<0.05$ was considered as significant.

\section{Results}

It was observed that most of the students (92.1\%) used to take powdered salt in their diet. 61 (6.4\%) of the students consumed crystalline (Pebble) salt and $14(1.5 \%)$ of the study subjects took both types of salt in their diet (Figure 1).

Out of 950 students, 915 salt samples were collected of which $79.0 \%$ of samples were iodized but only $16.1 \%$ of salt samples had $>15 \mathrm{ppm}$ iodine content while in $21.0 \%$ of samples, iodine content was nil. Most of the salt samples (33.7\%) had iodine content ranging between 1 to $7 \mathrm{ppm}$ (Figure 2).

(Table-1) depicts the results of salt storage and iodine content of salt samples. It was found that the percentage of nil iodine was highest in open packets $(35.7 \%)$ and it was lowest $(16.7 \%)$ when it was stored in airtight containers. Similarly, when salt was stored in open or closed containers (covered with a lid), the iodine content of $>15 \mathrm{ppm}$ was low as $14.3 \%$ and $11.1 \%$ respectively. Content of $>15 \mathrm{ppm}$ iodine in salt samples was highest in the case of storage in airtight containers (50.0\%). When iodine content in open packets and closed containers were compared with salt storage in airtight containers, a statistically very significant difference was found $\left(\chi^{2}=8.0\right.$, d.f. $=1, p$ $<.005)$.

Salt storage practices were checked on the spot in the families of students. Out of 70 families visited, salt was kept in containers in 36 (51.4\%) houses, and in the same open packets in which it was bought in 
$28(40.0 \%)$ houses. Only 6 (8.7\%) families were using airtight containers for storage of salt (Figure 3).

As shown in (Figure 4), salt storage (distance from chullha/stove) was related to the iodine content of salt. As the distance of salt storage from chullah increased, the level of iodine content in salt was also increased. Large numbers of salt samples, found with nil and 1-7 ppm iodine content were kept close to chullahi.e. $<1$ foot $(40.9 \%$ and $26.1 \%)$ and $1-5$ feet (54.6\% and $52.2 \%$ ) respectively. When iodine content of $<7 \mathrm{ppm}$ and $>7 \mathrm{ppm}$ was analyzed at a distance of $<5$ feet and $>5$ feet, a statistically significant difference was found $\left(\chi^{2}=4.9\right.$, d.f. $=1, p$ $<.05)$.

\section{Discussion}

In a study conducted in Karnataka, $72.1 \%$ of salt samples were of rock salt and only $27.9 \%$ were powdered salt samples. (12)

According to lodized Salt Coverage Study, $48.9 \%$ of households were using packaged powdered salt. (13) It must be noted that a higher percentage of using powdered salt could be because all powdered salt samples were packaged. Some powdered salt samples were obtained from the public distribution system which was though packaged in big carry bags but storage was poor. It was left opened leading to a reduction in the iodine content during storage in shops/stores. Another reason could be attributed to the fact that some crystalline forms of salt might be powdered at home. At many outlets, crystalline salt was available in the market, packed in big poly bags. Though the word "iodized" was printed on it iodine content was less than $15 \mathrm{ppm}$ in most of the samples. In a study conducted in Delhi, out of 230 subjects, most households (209) consumed packed refined salt. Only 21 households consumed unpacked crystalline salt.(14) This difference in consumption of the type of salt could be because the study was conducted in an urban area of Delhi and other sociodemographic factors might have affected the results. According to WHO/UNICEF/ICCIDD, $90 \%$ of the households should get iodized salt at the recommended level of $15 \mathrm{ppm}$.(15) In the present study, $16.1 \%$ of the households consumed iodized salt with the recommended level indicating that the Universal Salt lodization Programme is not very successful in Aligarh.

Similar observations were made in a study conducted in the Naugarh sub-division of Siddharth Nagar district where $12.6 \%$ of the subjects were consuming salt with the recommended level of iodine (>15 ppm). (16)

According to the global iodine nutrition scorecard (2012), 51.1\% of the Indian households were consuming iodized salt which also included the salt samples of $<15 \mathrm{ppm}$ iodine content.(17) Similar findings were found in the NFHS-3 survey where $24.0 \%$ salt samples had nil iodine (11) and similar observations were noticed in a study conducted in Panchmahal, Gujarat. (18)

Similar findings were also noticed in Karnataka where $16 \%$ of the population was consuming salt with an iodine content of $15 \mathrm{ppm}$ and more.(19) Similar results were also found in a study conducted in Ethiopia where the availability of adequately iodized salt was only $28.9 \%$.(20)

On the contrary, another study conducted in Karnataka showed that $50 \%$ of the people used salt with adequate iodine content. (12)

In the present study, the iodine content of salt was not satisfactory; households consuming adequately iodized salt (16.1\%) was far less than the recommended goal of $>90 \%$ coverage. This might be the reflection of a low level of awareness regarding the benefits of taking adequately iodized salt. For this information, education and communication activities in the district should be carried out more vigorously.

lodine stability and iodine losses in iodized salt following different storage methods had been evaluated by many studies in the world. ISCS showed that people stored their salt well, $84 \%$ in the container with lid, $8 \%$ in the container without lid, and $8.3 \%$ in bags.(13) Our results were comparable with the above findings.

In a study conducted in South Africa among patients suffering from hyperthyroidism, it was observed that only $1.6 \%$ of subjects stored salt in closed containers and away from sunlight, while open containers without lids were used by $49.2 \%$, and $36.1 \%$ of subjects stored it in rigid plastic containers with holes at the top, and $13.1 \%$ stored it in the open plastic bags in which the salt was bought. (21) Similar results were also found in a study conducted in Kenya where the loss of iodine was greater when iodized salt was stored in open polythene packets than in sealed packets or plastic or glass containers with lids. (22) In another study, it also was observed that the loss of iodine was greater when salt was stored in plastic bags than in glass bottles.(23) 
A significant reduction in salt iodine concentrations was also observed by the researchers when salt was stored close to the fireplace. (24) Our results were also confirmatory to the findings of a study conducted in Kanpur where the mean iodine content of the salt, stored at maximum distance from the cooking area was found to be higher. (25) The loss was greater in fortified salt stored at $37^{\circ} \mathrm{C}$ and under $76 \%$ humidity than at $20-25^{\circ} \mathrm{C}$ and under lower humidity. (23) Similar findings were also reported in Kenya and Ghana respectively. $(22,26)$

However, for better standing of loss of iodine from salt samples, other environmental factors such as duration of opening the packet, manufacturing date, the packaging material, and presence of impurities in salt should also be taken into consideration.

\section{Conclusion}

Out of 950 students, 915 salt samples were collected. It was observed that most of the students were taking powdered salt in their diet. Salt storage practices were checked on the spot in the families of students. Most of the students were taking iodized salt but only $16.1 \%$ of salt samples had $>15$ ppm iodine content. Out of 70 families visited, salt was kept in containers in most of the houses, and only (8.7\%) families were using airtight containers for storage of salt. It was found that the percentage of nil iodine was highest in open packets and it was lowest when it was stored in airtight containers. As the distance of salt storage from chullah/stove increased, the level of iodine content in salt was also increased.

School children and their families should be told about the correct salt storage practices like storage in airtight containers and it should be kept away from chullah/stove to minimize the evaporation of iodine from salt samples. Sustained IEC (Information, Education, and Communication) activities should be carried out more vigorously to sensitize the students and community to use adequately iodized salt.

At last, it is concluded that if all salt is iodized adequately and all families use only iodized salt with proper storage, then iodine deficiency will no longer threaten the health and development of children. This will help to build a healthy society and nation.

\section{Recommendation}

Sustained IEC (Information, Education and Communication) activities should be carried out to sensitize the people regarding importance of iodine in nutrition and salt storage practices. Periodical testing of salt samples should be carried out by the health worker, Anganwadi worker and ASHA.

\section{Limitation of the study}

Tests using STK provides qualitative information on the iodine content of salt samples. It estimates the percent of households using salt with no iodine, but will not provide accurate information on the percent using adequately iodized salt, or information on salt with excessive iodine. (10)

\section{Relevance of the study}

Salt is consumed universally in all socio-economic groups. Salt storage practices vary in the community and it affects the iodine content of the salt. If they are educated how to store salt in their houses, they will get adequate amount of iodine in their diet. Simple things make difference.

\section{Authors Contribution}

First and second authors developed the design of the work. First author collected the data, did data analysis and interpretation. First and second authors drafted the article. Second author and third author helped revised the article after their critical appraisal

\section{Acknowledgement}

We are thankful to our study subjects and health workers for their help and coordination.

\section{References}

1. Hetzel BS. lodine deficiency disorders (IDD) and their eradication. Lancet. 1983;2(8359):1126-9. doi: 10.1016/s0140-6736(83)90636-0. PMID: 6138653.[PubMed]

2. Ministry of Health and Family Welfare, Government of India; New Delhi, 2011. Department of Health and Family Welfare. Annual Report; 2010-2011. Available from: http://www.mohfw.nic.in/showfile.php?lid=767

[Accessed 27 Feb 2021].

3. Directorate General of Health Services, Govt. of India, New Delhi. National Goitre Control Programme. Prevalence Rate of Goitre According to Survey Conducted in Areas During 1981-2003. Available from: http://www.cbhidghs.nic.in/writereaddata/linkimages/101 75664079383.pdf. [Accessed 27 Feb 2021].

4. WHO. Vitamin and Mineral Nutrition Information System (VMNIS): Database on lodine Deficiency, World health organization, 2007. Available from: http://www.who.int/vmnis/iodine/status/summary/IDD e stimates table 2007.pdf. [Accessed 27 Feb 2021].

5. de Benoist B, McLean E, Andersson M, Rogers L. lodine deficiency in 2007: global progress since 2003. Food Nutr Bull. 2008;29(3):195-202. doi: 10.1177/156482650802900305. PMID: 18947032.[PubMed].

6. Directorate General of Health Services, Govt. Of India, New Delhi. National Goitre Control Programme. Prevalence Rate 
INDIAN JOURNAL OF COMMUNITY HEALTH / VOL 33 / ISSUE NO 01 / JAN-MAR2021 of Goitre According to Survey Conducted in Areas During 1981-2003. Available from: http://www.cbhidghs.nic.in/writereaddata/linkimages/101 75664079383.pdf . [Accessed 27 Feb 2021].

7. Anand $\mathrm{K}$, Pandav CS. Iodination of irrigation water. Natl Med J India. 1996;9(6):277-8. PMID: 9111789.[PubMed]

8. Rao PS, Richard J. Introduction to Biostatistics and Research Methods. 4th ed. New Delhi:P H I Learning Private Limited; 2009:195.

9. National Family Health Survey (NFHS-3) 2005-06. International Institute for Population Sciences (IIPS) and Macro International, 2007. Volume I. Ministry of Health and Family Welfare, Government of India. Mumbai:IIPS.

10. World Health Organization, United Nations Children's Fund, International Council for the Control of lodine Deficiency Disorders. Assessment of iodine deficiency disorders and monitoring their elimination. 3rd ed. Geneva: WHO;2007. Available from: http://apps.who.int/iris/bitstream/10665/43781/1/97892 41595827eng.pdf . [Accessed 27 Feb 2021].

11. National Family Health Survey (NFHS-3) 2005-06. International Institute for Population Sciences (IIPS) and Macro International, 2007. Volume I. Ministry of Health and Family Welfare, Government of India. Mumbai. Available from: usaid.gov/pdf_docs/ PNADK385.pdf. [Accessed 27 Feb 2021].

12. Kamath R, Bhat V, Rao RS, Acharya D, Kapil U, Kotian MS, Nayak DS. Prevalence of goitre among school children in Belgaum district. Indian J Pediatr. 2009;76(8):825-8. doi: 10.1007/s12098-009-0101-6. Epub 2009 Apr 15. PMID: 19381519.[PubMed].

13. lodized Salt Coverage Study, 2010. Office of Salt Commissioner, Govt. of India, 2010.

14. Agarwal S, Sethi V, Sharma D, Vaid M, Agnihotri A, Sindhwani A, Patra P. Consumption of iodized salt among slum households of north-East delhi, India. Indian J Community Med. 2009;34(4):368-9. doi: 10.4103/09700218.58406. PMID: 20165641; PMCID: PMC2822208.[PubMed].

15. WHO/UNICEF/ICCIDD. Assessment of iodine deficiency disorders and monitoring their elimination. A Guide for Programme Managers. $2^{\text {nd }}$ edn. WHO/NHD/01.1; 2001.

16. Chandra AK, Bhattacharjee A, Malik T, Ghosh S. Goiter prevalence and iodine nutritional status of school children
[Do salt storage...] | Ansari MA et al in a sub-Himalayan Tarai region of eastern Uttar Pradesh. Indian Pediatr. 2008;45(6):469-74. PMID: 18599931.[PubMed].

17. UNICEF. Monitoring the situation of children and women.2012 Available from: http://www.childinfo.org/idd profiles.php . [Accessed 27 Feb 2021].

18. Misra S, Kantharia SL, Damor JR. Prevalence of goitre in 6 12 years school- going children of Panchmahal district in Gujarat, India. Indian J Med Res. 2007;126(5):475-9. PMID: 18160754.[PubMed]

19. Kapil $U$, Singh $P$, Pathak $P$. Rapid survey of status of salt iodization and urinary iodine excretion levels in Karnataka, India. Current Science 2004;7(8):1058-60.

20. Gebremariam HG, Yesuf ME, Koye DN. Availability of adequately iodized salt at household level and associated factors in Gondar Town, Northwest Ethiopia. International Scholarly Research Notices Public Health 2013; 1-6.

21. Sebotsa MLD, Dannhauser A, Mollentze WF, Oosthuizen GM, Mahomed FA, Jooste PL. Knowledge, attitudes and practices regarding iodine among patients with hyperthyroidism in the Free State, South Africa. South African Journal of Clinical Nutrition 2009;22(1):18-21.

22. Kamau EW. A thesis submitted in partial fulfilment for the Degree of Master of Science in Food Science and Postharvest Technology in the Jomo Kenyatta University of Agriculture and Technology, Kenya 2007.

23. Wang GY, Zhou RH, Wang Z, Shi L, Sun M. Effects of storage and cooking on the iodine content in iodized salt and study on monitoring iodine content in iodized salt. Biomed Environ Sci. 1999;12(1):1-9. PMID: 10442215.[PubMed].

24. Abeysuriya V, Wickremasinghe AR, Perera PJ, Kasturiratne A. Consumption pattern of iodised salt in households and serum TSH levels among 5-9 year old children in the plantation sector of Sri Lanka. Ceylon Med J. 2012 Jun;57(2):69-74. doi: 10.4038/cmj.v57i2.4459. PMID: 22772784. [PubMed]

25. Singh $S$, Singh R. Prevalence of goitre and iodine intake in Kanpur. IOSR Journal of Nursing and Health Science 2013;2(1):22-26.

26. Laar C, Pelig-Ba KB. Effect of exposure and storage conditions on the levels of iodine in selected iodated and non-iodated salts in Ghana. Pakistan Journal of Nutrition 2013;12(1):34-39.

\section{Tables}

\section{TABLE 1 STORAGE OF SALT AND IODINE CONTENT OF SALT (PPM)}

\begin{tabular}{|c|c|c|c|c|c|c|c|c|c|c|c|}
\hline \multirow[t]{3}{*}{ S. No. } & \multirow[t]{3}{*}{ Storage } & \multicolumn{8}{|c|}{ lodine Content (ppm) } & \multicolumn{2}{|c|}{ Total } \\
\hline & & \multicolumn{2}{|c|}{0} & \multicolumn{2}{|c|}{ 01--07 } & \multicolumn{2}{|c|}{ 08--15 } & \multicolumn{2}{|c|}{$>15$} & & \\
\hline & & No. & $\%$ & No. & $\%$ & No. & $\%$ & No. & $\%$ & No. & $\%$ \\
\hline 1 & Open Packet & 10 & 35.7 & 13 & 46.4 & 1 & 3.6 & 4 & 14.3 & 28 & 40 \\
\hline 2 & Closed Container & 9 & 25 & 21 & 58.3 & 2 & 5.6 & 4 & 11.1 & 36 & 51.4 \\
\hline 3 & Airtight Container & 1 & 16.7 & 1 & 16.7 & 1 & 16.7 & 3 & 50 & 6 & 8.6 \\
\hline & Total & 20 & 28.6 & 35 & 50 & 4 & 5.7 & 11 & 15.7 & 70 & 100 \\
\hline
\end{tabular}




\section{Figures}

FIGURE 1TYPE OF SALT CONSUMED BY THE STUDY POPULATION

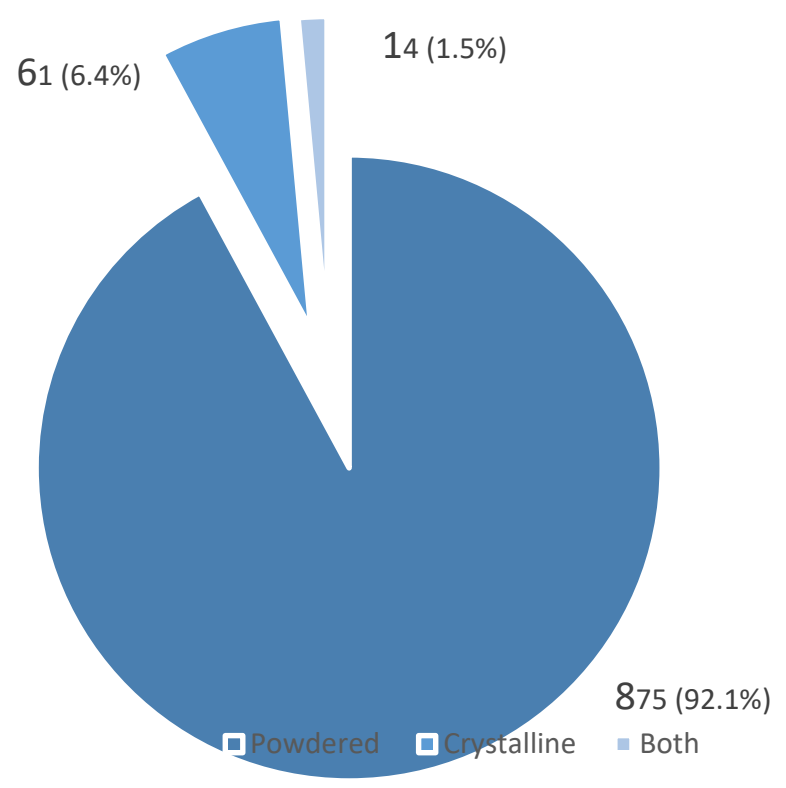

FIGURE 2 IODINE CONTENT OF SALT SAMPLES

(21.0\%)




\section{FIGURE 3 SALT STORAGE PRACTICES}

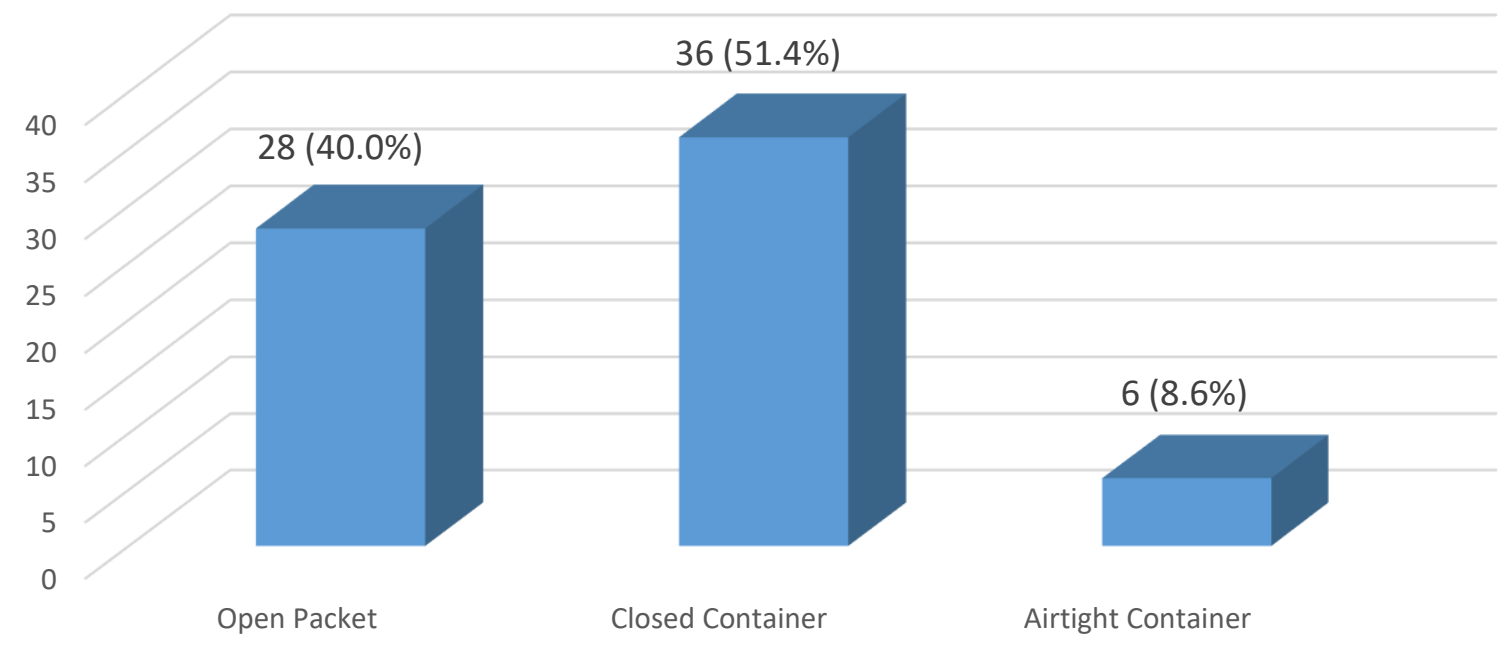

- Series1

FIGURE 4 DISTANCE OF SALT STORAGE FROM CHULLAH AND IODINE CONTENT

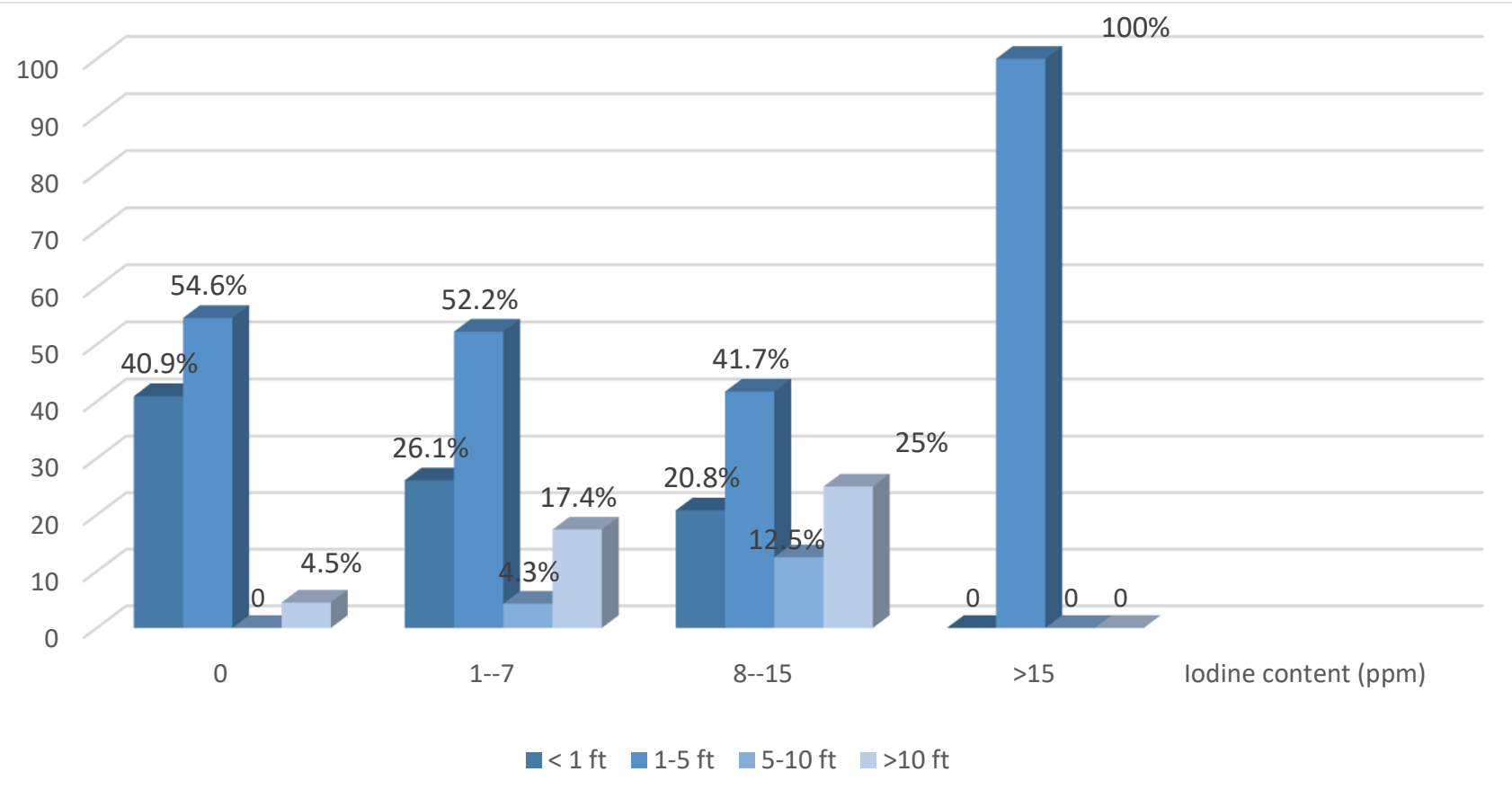

